Esta revista forma parte del acervo de la Biblioteca Jurídica Virtual del Instituto de Investigaciones Jurídicas de la UNAM

\title{
Diagnóstico del modelo de fiscalización electoral mexicano
}

\section{Oswaldo Chacón Rojas*}

\section{Sumario:}

I. El desafío del control del dinero en las elecciones

II. Características generales del modelo de fiscalización electoral en México

III. Justificación y objetivos del estudio "Diagnóstico de las fortalezas y debilidades del andamiaje normativo de la fiscalización electoral en México"

IV. Resumen de hallazgos destacados

V. A modo de propuestas

VI. Fuentes consultadas

* Doctor en Teoría Política por la Universidad Autónoma de Madrid; profesor de Derecho Electoral en el Centro de Investigaciones Jurídicas de la Universidad Autónoma de Chiapas; investigador nacional nivel 1. 
Esta revista forma parte del acervo de la Biblioteca Jurídica Virtual del Instituto de Investigaciones Jurídicas de la UNAM www.juridicas.unam.mx

\section{Resumen:}

El uso de recursos económicos se ha constituido como un elemento imprescindible en la competencia democrática. Pero su falta de regulación es capaz de producir distorsiones importantes en el proceso democrático (plutocracias, capturas de las agendas del Estado por grandes grupos económicos, o bien del crimen organizado y/o narcotráfico). México cuenta con uno de los marcos regulatorios más robustos del mundo, y a pesar de ello el modelo fue constantemente cuestionado durante las contiendas presidenciales de 2012, por lo que es evidente la necesidad de fortalecer el andamiaje legal e institucional en este ámbito. El objetivo de este trabajo es la realización de un diagnóstico integral del modelo y proponer algunas medidas para su fortalecimiento. ${ }^{1}$

Palabras clave: elecciones, financiamiento político, equidad, rendición de cuentas.

1 La presente investigación ha sido desarrollada por el Centro de Investigaciones Jurídicas de la Universidad Autónoma de Chiapas, y auspiciada por el Programa de Naciones unidas para el Desarrollo en México, el Tribunal Electoral del Poder Judicial de la Federación y el Instituto Federal Electoral. Ha sido coordinada por el doctor Oswaldo Chacón Rojas, y han participado como investigadores el doctor Carlos Natarén Nandayapa, maestro Omar David Jiménez Ojeda, doctor Guillermo Nieto Arreola, maestra Karla Georgina Morales Aguilar, y como asistentes de investigación maestra Azarel Enríquez Ríos, licenciado Mauricio Corzo, licenciado Marisela Hazzel Pacheco Pazos, licenciado Mireya Camacho Morales y Veronica Monjaraz Hernández. 


\section{El desafío del control del dinero en las elecciones}

Uno de los temas que ha adquirido mayor relevancia en los estados democráticos contemporáneos es el relativo a la fiscalización de los recursos de las entidades públicas. En particular, la fiscalización de los fondos partidistas y electorales ha generado un inusitado interés en los últimos años tanto en aquellos países que recientemente han transitado a la democracia, principalmente de Latinoamérica y Europa del este, como en las democracias consolidadas.

Su relevancia ha venido a la par con el incremento y generalización de escándalos de corrupción financiera en campañas electorales como en Argentina, Brasil, Canadá, Colombia, Francia, Alemania, Japón, Sudáfrica, el Reino Unido o los Estados Unidos, sólo por mencionar algunos casos. ${ }^{2}$ Los escándalos en esta materia resultan especialmente alarmantes en América Latina incluyendo, por supuesto, a México, donde la sospecha del uso indiscriminado de recursos financieros de dudosa procedencia ha estado presente en diversos procesos electorales, como en las elecciones de presidenciales de 1994 con el caso Cabal Peniche, o de 2000 con los casos conocidos como Pemexgate y Amigos de Fox. ${ }^{3}$

En septiembre de 2012, la Comisión Global sobre Elecciones, Democracia y Seguridad, encabezada por el ex secretario general de la ONU, Kofi Annan, y en el que participan ex líderes mundiales y ganadores del premio Nobel así como académicos especialistas, publicó un informe en donde se identificó al notorio aumento del financiamiento político "no controlado, no revelado, ilegal y opaco" en todo el mundo como una de las principales amenazas para la integridad electoral en las democracias contemporáneas. ${ }^{4}$

2 Cfr. Daniel Zovatto, "América Latina", en Carrillo, Manuel et al. (coords.), Dinero y contienda político-electoral. Reto de la democracia, México, FCE, 2003.

3 Cfr. Córdova, Lorenzo y Murayama, Ciro, Elecciones, dinero y corrupción. Pemexgate y Amigos de Fox, México, Cal y Arena, 2006, pp. 39 y 111.

${ }_{4}$ El informe se centró en una serie de problemas, incluyendo la violencia posterior a las elecciones en lugares como Kenia y Nigeria, las finanzas ilícitas en Costa Rica, y las poblaciones marginadas en Europa. Global Commision on Elections, Democracy and Security, Deepening Democracy: A strategy for improving the integrity of elections worldwide, septiembre de 2012, en http://www.global-commission.org/sites/global-comm ission. org/files/DeepeningDemocracyFinalReport.pdf, consultada el 2 de febrero de 2013. 
Esta revista forma parte del acervo de la Biblioteca Jurídica Virtual del Instituto de Investigaciones Jurídicas de la UNAM

El informe sostiene que a partir de la Declaración Universal de Derechos Humanos y del Pacto Internacional de Derechos Civiles y Políticos, existen principios fundamentales y normas bien definidas que deben conducir a la celebración de las elecciones con integridad. Sin embargo, dicha integridad se encuentra amenazada por cinco factores, dentro de los que destaca el financiamiento político descontrolado, no revelado y "turbio", derivado principalmente de las dificultades para controlar el exceso de fondos particulares no reportados, la falta de sanción al cuantioso desvío de recursos públicos con fines electorales, así como la debilidad institucional en varios países para blindar sus procesos electorales de la injerencia de fondos del crimen organizado. ${ }^{5}$ Esta situación podría robarle a las democracias afectadas su fortaleza para promover la igualdad política, el empoderamiento de los marginados y la capacidad para manejar conflictos sociales pacíficamente. De ahí que el informe concluya que en todas las democracias, sean ricas y pobres, viejas o nuevas, la deficiente regulación del financiamiento de las campañas políticas es una grave amenaza para el logro de elecciones con integridad.

Desde la teoría democrática siempre se ha aceptado que para financiar su funcionamiento, y en particular sus campañas electorales, los candidatos y partidos políticos necesitan recursos económicos. Sin embargo, con el fin de poner fin a los efectos corrosivos sobre la integridad de las elecciones y la democracia, los gobiernos deben controlar con rigor el financiamiento político. Cuando este control no existe o es deficiente, no puede garantizarse la celebración de elecciones libres, la equidad en las contiendas, la imparcialidad del árbitro, ni la transparencia de los gobiernos electos.

En la actualidad encontramos importantes esfuerzos legislativos en ese sentido, principalmente regulaciones en torno al financiamiento y al gasto electoral, en prácticamente todas las democracias del mundo (la excepción es Suiza). Las reglas de financiamiento, es decir, la regulación del flujo de recursos económicos hacia la actividad política, se expresan mediante la restricción o prohibición del uso de ciertas fuentes de financiamiento, también llamadas regulaciones "negativas", así como a través de la provisión o el estímulo del uso de otras fuen-

Para mayor abundamiento en este último tema $c f r$. Chacón Rojas, Oswaldo, Dinero del crimen organizado y fiscalización electoral, México, Fontamara, 2011. 
Esta revista forma parte del acervo de la Biblioteca Jurídica Virtual del Instituto de Investigaciones Jurídicas de la UNAM

tes de financiamiento, llamadas regulaciones "positivas", o bien, una combinación de éstas.

Las regulaciones "positivas" se expresan en tres formas: a) financiamiento público; $b$ ) financiamiento privado, y $c$ ) financiamiento mixto, que permite el uso de los dos tipos de financiamiento electoral. El financiamiento público comprende diversas formas de subvención, tanto directas (en dinero o bonos) como indirectas (servicios, beneficios tributarios, capacitación, etcétera). Mientras los subsidios directos proveen de recursos económicos líquidos a los partidos y candidatos, los indirectos les otorgan, en general, recursos en especie. La idea general detrás de la financiación pública es que las actividades políticas no son posibles sin dinero, y que la provisión de fondos de manera "regulada" puede ayudar a fomentar el pluralismo político y a contrarrestar el papel negativo del dinero en la política. ${ }^{6}$

El financiamiento privado, es decir, aquel que no proviene de las arcas públicas, se permite en casi la totalidad de los países analizados, aunque siempre sujeto a reglas. Se suele regular el financiamiento privado electoral para evitar dos situaciones: presiones de los donantes hacia los candidatos para que las políticas públicas favorezcan sus intereses particulares, a veces en desmedro del bien común, y presión por parte de los candidatos y partidos políticos para que los individuos realicen donaciones en su favor, ya sea extorsionándolos u ofreciéndoles prebendas públicas.

En la base de datos de IDEA se identifican tres tipos de restricciones que son más comunes en la mayoría de los países: aportaciones de $a$ ) intereses extranjeros, $b$ ) fuentes anónimas, y c) recursos del Estado (este último sin incluir el suministro de financiamiento público regulado). ${ }^{7}$

${ }^{6}$ De un universo de 116 países analizados en el estudio comparativo de IDEA (2012), el $68 \%$ de ellos cuentan con disposiciones para el financiamiento público directo a los partidos políticos. Ningún país cuenta exclusivamente con financiamiento público electoral. Esto es, los países que contemplan ese tipo de financiamiento, lo acompañan de la posibilidad de allegarse de aportaciones privadas. En consecuencia, la mayor parte de los países se adscribe al modelo de financiamiento mixto.

7 También puede consultarse el estudio comparativo de financiamiento electoral que abarca distintos países, en Ferreira Rubio, Delia (ed.), Financiamiento de partidos políticos, Buenos Aires, Centro Interdisciplinario de Estudios sobre el Desarrollo Latinoamericano-Konrad Adenauer Stiftung, 1997; Castillo, Pilar del y Zovatto, Daniel (eds.), La financiación de la política en Iberoamérica, San José, Costa Rica, Instituto Interamericano de Derechos Humanos, 1998. 
Esta revista forma parte del acervo de la Biblioteca Jurídica Virtual del Instituto de Investigaciones Jurídicas de la UNAM

Además de prohibiciones totales a ciertos tipos de aportaciones, en la normatividad internacional encontramos aportaciones que si bien son válidas están sujetas a límites cuantitativos. Los más comunes son: a) los límites de la cantidad que un donante puede dar a un partido político durante un periodo de tiempo determinado (normalmente un año); b) los límites a las donaciones permitidas en una elección, y c) los límites a las donaciones que se hagan a los candidatos.

La fiscalización electoral se basa en el control de este tipo de regulaciones sobre el ingreso financiero de los partidos políticos y candidatos, pero también en el control de regulaciones sobre el egreso o gastos de los mismos, a efecto de procurar mayor igualdad en las oportunidades de triunfo electoral entre los contendientes, contener el gasto electoral, reducir la probabilidad de captura de líderes y representantes, y prevenir el financiamiento de la política con dinero ilegal. Generalmente las reglas de gasto se refieren a restricciones en cuanto a los montos que pueden erogarse en determinadas actividades electorales (topes de gasto a rubros específicos), y regulaciones respecto de quién o quiénes pueden gastar en ellas y cómo deben de hacerlo. Las actividades en las cuales encontramos mayores restricciones de gasto, son aquellas relacionadas a la publicidad en medios electrónicos y a la compra de votantes.

Asimismo, las reglas de financiamiento y gasto electoral suelen acompañarse del establecimiento de procedimientos y sanciones para hacerlas valer, principalmente la obligación partidista de presentar informes financieros, la creación de instituciones para revisarlos e investigarlos, así como la presencia de un régimen de sanciones en caso de incumplimientos. Las sanciones son variadas, y van desde amonestaciones, multas, reducción de ministraciones del financiamiento público que les corresponda, la supresión total de la entrega de las ministraciones del financiamiento, la negativa del registro de las candidaturas, hasta la suspensión o cancelación de su registro como partido político.

\section{Características generales del modelo de fiscalización electoral en México}

El modelo vigente de control fue consecuencia de sucesivas reformas constitucionales y legales a partir de 1986-87, en la cual se establecieron 
Esta revista forma parte del acervo de la Biblioteca Jurídica Virtual del Instituto de Investigaciones Jurídicas de la UNAM

criterios claros para la asignación de recursos financieros para los partidos políticos, dependiendo de su porcentaje de votos y su número de diputados, hasta la última aprobada en noviembre de 2007, en donde se promovióla prohibición de contratación de publicidad política electoral en radio y televisión por parte de partidos, candidatos y particulares, se eliminó el secreto bancario como límite a las investigaciones del Instituto Federal Electoral (IFE), y se impulsó la especialización de la función fiscalizadora al crear una Unidad de Fiscalización con autonomía técnica, la cual fue dotada de nuevas y mejores herramientas de investigación y sanción. Los elementos característicos del modelo son los que a continuación se explican.

\section{Existencia de un organismo fiscalizador autónomo}

México forma parte de la tendencia en el mundo, pues la competencia de fiscalizar el dinero político electoral recae en un órgano del Estado, cuya naturaleza es administrativa y autónoma. La función fiscalizadora del IFE es realizada a través de un órgano técnico especializado, denominado Unidad de Fiscalización de los Recursos de los Partidos Políticos (UFRPP). Este modelo vino a sustituir en 2007 a la anterior Comisión de Fiscalización de los Recursos de los Partidos y Agrupaciones Políticas del Consejo General del IFE, la cual se integraba exclusivamente por consejeros electorales (artículo 77.6).

\section{Reglas de financiamiento electoral}

En México se ha optado por un modelo de financiamiento mixto que privilegia los fondos públicos y establece prohibiciones y limitaciones a las aportaciones privadas. El financiamiento público es proporcionado por el Estado a través del IFE, y consiste en dinero entregado directamente a cada instituto político, para cubrir los gastos de las actividades ordinarias permanentes, para sufragar las actividades extraordinarias de consecución del voto, o como una prerrogativa en cuanto a servicios, infraestructura, exenciones, acceso a los medios de comunicación (artículo 41 constitucional). También se establecen las obligaciones para realizar actividades que tienden a la obtención del voto. Para tal efecto, el financiamiento público anual es proporcionado en efectivo o en especie, como lo prevé el Código Electoral. 
Esta revista forma parte del acervo de la Biblioteca Jurídica Virtual del Instituto de Investigaciones Jurídicas de la UNAM

El monto del financiamiento público anual para el sostenimiento de las actividades ordinarias permanentes se determina multiplicando el número total de ciudadanos inscritos en el padrón electoral, a la fecha de corte de julio de cada año, por el 65\% del salario mínimo diario vigente para el Distrito Federal. En cada renovación del Poder Ejecutivo y de ambas cámaras, se asigna un monto equivalente al 50\% del financiamiento público para actividades ordinarias permanentes que le correspondan en ese año. El financiamiento se reparte conforme a las siguientes reglas: $30 \%$ del total se entrega de manera igualitaria a los partidos, y $70 \%$ según el porcentaje de la votación nacional emitida que hubiese obtenido cada partido político en la última elección.

Por otro lado, el sistema electoral mexicano contempla también el financiamiento de origen privado, que comprende: $a$ ) aportaciones de los militantes y cuotas voluntarias de los propios candidatos a sus campañas; $b$ ) aportaciones de simpatizantes; $c$ ) autofinanciamiento, y d) rendimientos por fondos bancarios. Las aportaciones privadas están restringidas para algunos sectores como las dependencias públicas, las iglesias, personas morales con fines de lucro o extranjeros, y sus montos nunca pueden ser mayores a los fondos públicos.

\section{Reglas de gasto electoral}

Los partidos pueden gastar en todo lo concerniente a las actividades electorales. La legislación establece que dichos gastos pueden ser de propaganda, operativos y de gastos de producción de los mensajes para radio y televisión. Los primeros comprenden los realizados en medios impresos (diarios, revistas y similares), bardas, mantas, volantes, pancartas, equipos de sonido, eventos políticos realizados en lugares alquilados, propaganda utilitaria y otros relacionados; por su parte, los gastos operativos comprenden los sueldos y salarios del personal eventual, arrendamiento eventual de bienes muebles e inmuebles, gastos de transporte de material y personal, viáticos y otros similares.

La ley electoral precisa que no se consideran dentro de los topes de campaña los gastos que realicen los partidos para su operación ordinaria y para el sostenimiento de sus órganos directivos y de sus organizaciones. El gasto en actividades ordinarias permanentes es aquel que se destina para apoyar las actividades ordinarias de los partidos, 
Esta revista forma parte del acervo de la Biblioteca Jurídica Virtual del Instituto de Investigaciones Jurídicas de la UNAM

mientras que los gastos de campaña son exclusivamente para financiar actividades destinadas a la obtención del voto y, por tanto, sólo se asigna en los años en que hay campañas electorales.

Respecto de quién puede gastar, conforme a la normatividad electoral vigente, es una función que recae directa y exclusivamente en los partidos políticos y, en su caso, coaliciones. La ley o el reglamento, establecen la obligación de cada precandidato o candidato según sea el caso, de nombrar a un representante financiero. La norma establece la obligatoriedad del manejo de los recursos a través de cuentas bancarias abiertas exclusivamente a nombre del partido político.

Como consecuencia de la reforma de 2007, los partidos y candidatos tienen prohibido gastar en la contratación de espacios en radio y televisión. El uso de la radio y la televisión se limita para fines electorales sólo a los tiempos gratuitos que corresponden por ley al Estado y dispone que su administración será desarrollada en exclusiva por el IFE (apartado A del artículo 41 constitucional). En consecuencia, los partidos políticos en ningún momento pueden contratar o adquirir, por sí o por terceras personas, tiempos en cualquier modalidad de radio y televisión. ${ }^{8}$

El Código Federal de Instituciones y Procedimientos Electorales (Cofipe) dispone, en su artículo 182-A, que los gastos que realicen los partidos políticos, las coaliciones y sus candidatos en la propaganda electoral y las actividades de campaña, no podrán rebasar los topes que para cada elección acuerde el Consejo General. El tope máximo de gastos de campaña será equivalente al $20 \%$ del financiamiento público de campaña establecido para todos los partidos en el año de la elección presidencial. ${ }^{9}$

8 Murayama, Ciro, "Consecuencias económicas de la reforma electoral", Nexos, México, octubre de 2007, http://www.nexos.com.mx/?P=leerarticulo\&Article $=660960$.

9 De acuerdo a lo anterior, en el proceso electoral 2012, el tope de gastos para presidente de la República fue de: $\$ 67222416.83$ pesos para precampaña y $\$ 336112084.16$ pesos para la campaña electoral. Fuente IFE, Comunicado de prensa de 23 de noviembre de 2011. Acuerdo General del IFE, sesión extraordinaria del Consejo General celebrada el 16 de diciembre de 2011 CG434/2011 (presidente), CG435/2011 (senador), CG436/2011 (diputados), en http://www.ife.org.mx/documentos/proceso_2011-2012/preparacion.html, consultada el 2 de febrero de 2013. 
Esta revista forma parte del acervo de la Biblioteca Jurídica Virtual del Instituto de Investigaciones Jurídicas de la UNAM

\section{Procedimiento de revisión y verificación de los informes financieros partidistas}

Los partidos están obligados a presentar informes financieros posteriormente a la culminación del ejercicio de que se trate (financiamiento anual, precampañas o campañas), a efecto de que la UFRPP pueda verificar el cumplimiento de las reglas de financiamiento y gasto electoral (artículo 83 del Cofipe). Tras la presentación del informe, la UFRPP dispone de ciento veinte días para revisarlo. El procedimiento de revisión y dictamen de los informes de campaña se realiza en cuatro etapas:

En la primera etapa, se realiza una revisión de gabinete en la que se determinan los errores y omisiones de carácter técnico que presentan los Informes de Campaña, a fin de solicitar a los partidos políticos las aclaraciones correspondientes.

En la segunda etapa, se lleva a cabo la revisión documental exhaustiva y detallada de los soportes de los ingresos y egresos reportados de acuerdo con los criterios y procedimientos establecidos.

En la tercera etapa, se efectúa una verificación de la documentación necesaria para comprobar la veracidad de lo reportado por los partidos políticos en sus informes. A primera vista podrá parecer suficiente que las cuentas de gastos coincidan con los comprobantes originales analizados mediante procedimientos de cotejo con la contabilidad, sin embargo, es posible que existan sobreestimaciones, alteraciones y errores. Por ello la UFRPP realiza actividades de investigación, para lo cual se apoya en órganos auxiliares, como lo son las juntas locales y distritales del IFE que apoyan su labor en la notificación de diversas determinaciones como solicitudes de información y confirmaciones a sujetos obligados y terceros relacionados; también auxilian en el monitoreo de medios impresos, propaganda móvil y fija. La verificación de la UFRPP se realiza de acuerdo a una metodología muestral, ${ }^{10} \mathrm{y}$ aplicando procedimientos de auditoría adicionales a los procedimientos de revisión documental que usualmente se practican, como son las

10 Es pertinente recordar que, en la sentencia que recayó al recurso de apelación SUPRAP-017/97, del 26 de junio de 1997, el Tribunal Electoral del Poder Judicial de la Federación estableció que el ente fiscalizador puede determinar realizar pruebas selectivas, como forma y método a seguir para llevar a cabo la revisión de los informes, "sin que ello sea contrario a las prácticas que se siguen en los procedimientos de auditoría”. 
Esta revista forma parte del acervo de la Biblioteca Jurídica Virtual del Instituto de Investigaciones Jurídicas de la UNAM

visitas de verificación, verificaciones in locuo y los monitoreos, cotejos, o confirmaciones de operaciones con terceros (circularizaciones), así como instrumentos de investigación como el acceso a información bancaria y fiscal anteriormente reservada, el requerimiento de información a personas físicas y morales, o el intercambio de información con otras autoridades como la Unidad de Inteligencia Financiera de la SHCP, la Comisión Nacional Bancaria, el SAT o la PGR.

Por último, se elabora el Dictamen Consolidado para su presentación al Consejo General del Instituto, en los términos dispuestos por el Código de la materia.

\section{Régimen de sanciones}

El modelo se complementa con el establecimiento de un régimen de sanciones. El Código dispone que el Consejo General del IFE, no la UFRPP, sea quien está facultado para fijar la sanción correspondiente a partir de las revisiones de los auditores a los reportes financieros. El Cofipe dispone sobre este tema en el artículo 269 lo siguiente:

Los partidos políticos y las agrupaciones políticas, independientemente de las responsabilidades en que incurran sus dirigentes, miembros o simpatizantes, podrán ser sancionados:

- Con amonestación pública;

- Con multa de 50 a 5 mil días de salario mínimo general vigente para el Distrito Federal;

- Con la reducción de hasta el 50\% de las ministraciones del financiamiento público que les corresponda, por el período que señale la resolución;

- Con la supresión total de la entrega de las ministraciones del financiamiento que les corresponda por el período que señale la resolución;

- Con la negativa del registro de las candidaturas;

- Con la suspensión de su registro como partido político o agrupación política, $y$

- Con la cancelación de su registro como partido político o agrupación política.

Como se puede observar, el régimen de sanciones descansa fundamentalmente en la imposición de sanciones de carácter pecuniario, 
Esta revista forma parte del acervo de la Biblioteca Jurídica Virtual del Instituto de Investigaciones Jurídicas de la UNAM

con la ventaja de que una vez que estén firmes pueden ser descontadas de las ministraciones del financiamiento público que les corresponde a los partidos infractores. Para imponer una sanción más trascendente, como la supresión total de ministraciones, o la pérdida o suspensión del registro, la infracción debe ser grave, es decir, con todas las agravantes del caso y reiterada.

\section{Justificación y objetivos del estudio "Diagnóstico de las fortalezas y debilidades del andamiaje normativo de la fiscalización electoral en México"}

Aun cuando el establecimiento de marcos regulatorios de financiamiento y gasto electoral ha sido significativo, tomando en cuenta que hasta hace algunos años en la mayoría de las democracias el tema había sido ignorado, es preocupante que los avances no han logrado mitigar los retos y cuestionamientos de la ciudadanía ni de los propios actores políticos. De acuerdo con el Informe de la Comisión Global ${ }^{11}$ sobre Elecciones, Democracia y Seguridad, la escalada de conflictos poselectorales relacionados con el dinero en las campañas ha ido en aumento. Los cuestionamientos se han presentado independientemente del avance regulatorio en cada país, tanto en aquellos cuyas restricciones y garantías de control son mínimas, como en aquellos que han logrado consolidar un andamiaje de reglas y controles en su normatividad.

En este segundo supuesto se encuentra México, país que a pesar de contar con uno de los marcos regulatorios del financiamiento y gasto electoral más completos del mundo, aún se encuentra bajo permanentes cuestionamientos y quejas de los actores políticos y opinión pública sobre los efectos distorsionadores del dinero en sus procesos electorales. Como consecuencia de las reformas constitucionales de 1986-87, 1990, 1993, 1994, 1996 y 2007, así como mediante criterios establecidos en resoluciones jurisdiccionales por parte del Tribunal Electoral del Poder Judicial de la Federación (TEPJF), se ha consolidado uno de los modelos más completos en el mundo, con mayores reglas, mayores

${ }^{11}$ Global Commision on Elections, Democracy and Security, cit. 
Esta revista forma parte del acervo de la Biblioteca Jurídica Virtual del Instituto de Investigaciones Jurídicas de la UNAM

restricciones y prohibiciones, y con un organismo autónomo, especializado, dotado de instrumentos de control, verificación y sanción para hacer respetar dichas reglas como es la Unidad de Fiscalización de los Recursos de los Partidos Políticos (UFRPP) del IFE. Pero a pesar de haber consolidado este intricado andamiaje, los procesos electorales siguientes, las elecciones intermedias legislativas de 2009 y en especial las coincidentes con la presidencial de 2012, se han caracterizado desde su inicio por una inusitada y permanente presencia de reclamos, cuestionamientos, descalificaciones y quejas, relacionadas a supuestas violaciones a las reglas de financiamiento y gasto electoral, contando para ello con novedosas plataformas mediáticas.

Las quejas y cuestionamientos al modelo de control de las reglas de financiamiento y gasto electoral fueron una constante en la elección presidencial de 2012 en México, y el argumento principal de los recursos presentados en la fase impugnativa de la elección. Por lo tanto, es obvio que a pesar del avance regulatorio mexicano estamos hablando de un esfuerzo marcadamente insuficiente, de un modelo que no responde a las expectativas de los actores políticos y de gran parte de la opinión pública, y necesita ser analizado.

De ahí la importancia y conveniencia de realizar un estudio integral sobre el andamiaje normativo de la fiscalización electoral en México, el cual fue el objetivo del proyecto "Diagnóstico de las fortalezas y debilidades de la fiscalización electoral en México” desarrollado por el Centro de Investigaciones Jurídicas de la UNACH y auspiciado por el Programa de Naciones Unidas para el Desarrollo en México, el TEPJF y el IFE.

\section{Resumen de hallazgos destacados}

El control del financiamiento ilegal electoral ha sido poco estudiado académica y empíricamente. Es un tema tradicionalmente ignorado en los estudios sobre partidos políticos, los que han puesto énfasis en su financiamiento, pero han obviado el tema del control. No está presente en los clásicos como Weber (1967), Duverger (1957) o Sartori (1980), ni en los críticos como Ostrogorski (1902), Michels (1911) o Epstein (1967). Ha sido evidente la falta de una teoría sobre la fiscalización electoral, y llama la atención que el auge regulativo de los últi- 
Esta revista forma parte del acervo de la Biblioteca Jurídica Virtual del Instituto de Investigaciones Jurídicas de la UNAM

mos años tampoco esté siendo acompañado de los suficientes estudios académicos. Los trabajos más importantes son aquellos que han intentado sistematizar los marcos regulatorios en el mundo, principalmente los realizados por reconocidas agencias internacionales como IDEA, ${ }^{12}$ o IFES. ${ }^{13}$

En consecuencia, en esta investigación nos aproximamos al modelo de fiscalización electoral mexicano al margen de modelos preconcebidos, y el análisis doctrinal y jurídico de su andamiaje normativo se acompaña con la utilización de herramientas propias de la metodología cualitativa, principalmente cuestionarios y entrevistas a profundidad a los actores del proceso de fiscalización, como son los representantes financieros de los partidos políticos y los funcionarios electorales responsables de la aplicación de las reglas, lo cual nos ha permitido obtener información sobre la operatividad real del modelo, fortalecer el diagnóstico de la situación, y atender las lagunas informativas presentes en algunas etapas del proceso. Del desarrollo de dicha estrategia metodológica se identificaron los siguientes hallazgos destacados:

12 Political Finance Regulations around the World. An Overview of the International IDEA Database, disponible en http://www.idea.int/publications/political-finance-regulations/loader.cfm?csModule=security/getfileepageid=52121, onsultada el 2 de febrero de 2013.

${ }_{13}$ Political finance regulation: The Global Experiencie, disponible en http://www. ifes.org/ /media/Files/Publications/Books/2009/Political\%20Finance\%20Regulation\%20 The\%20Global\%20Experience/Political_Finance_Regulation_The_Global_Experience. pdf, consultada el 2 de febrero de 2013. 
Esta revista forma parte del acervo de la Biblioteca Jurídica Virtual del Instituto de Investigaciones Jurídicas de la UNAM www.juridicas.unam.mx

1. Etapa de integración y presentación del informe por el partido, agrupación u organización política

Gráfica 1. Problemáticas de mayor incidencia en la responsabilidad de los candidatos durante el proceso de integración de los informes de precampaña y campaña

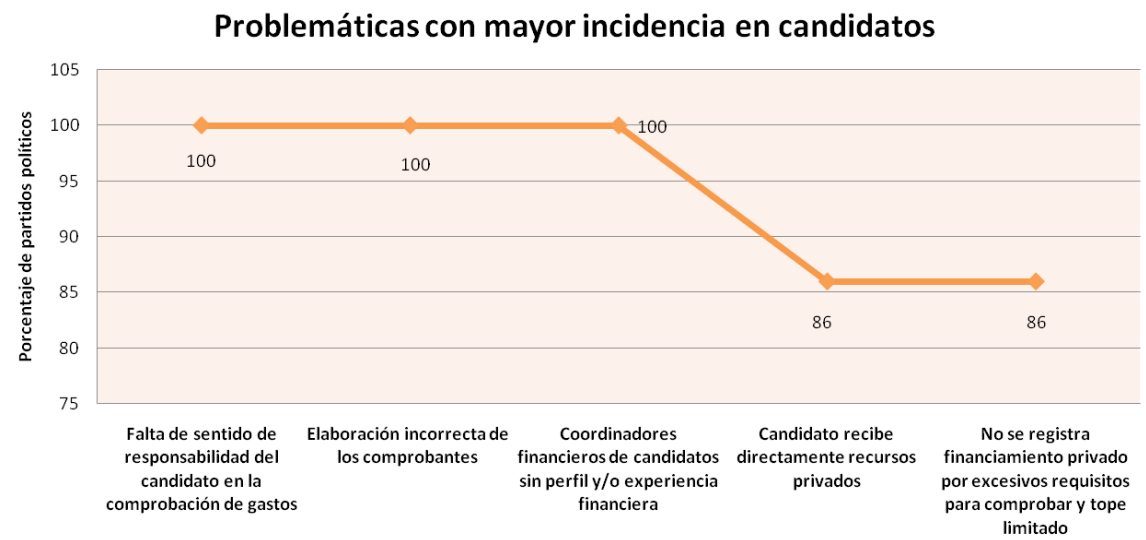

Gráfica 1. Problemáticas de mayor incidencia en la responsabilidad de los candidatos durante el proceso de integración de los informes de precampaña y campaña (continuación)

\section{Problemáticas con mayor incidencia en candidatos ( 2 a parte)}
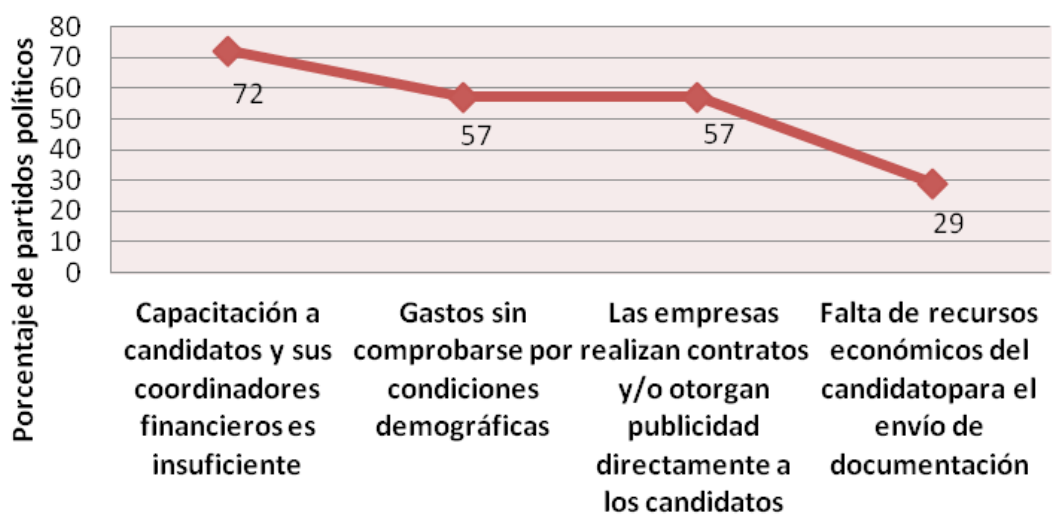
Esta revista forma parte del acervo de la Biblioteca Jurídica Virtual del Instituto de Investigaciones Jurídicas de la UNAM

\begin{abstract}
Gráfica 2. Problemáticas de mayor incidencia en la responsabilidad de los partidos durante el proceso de integración de los informes de precampaña y campaña
\end{abstract}

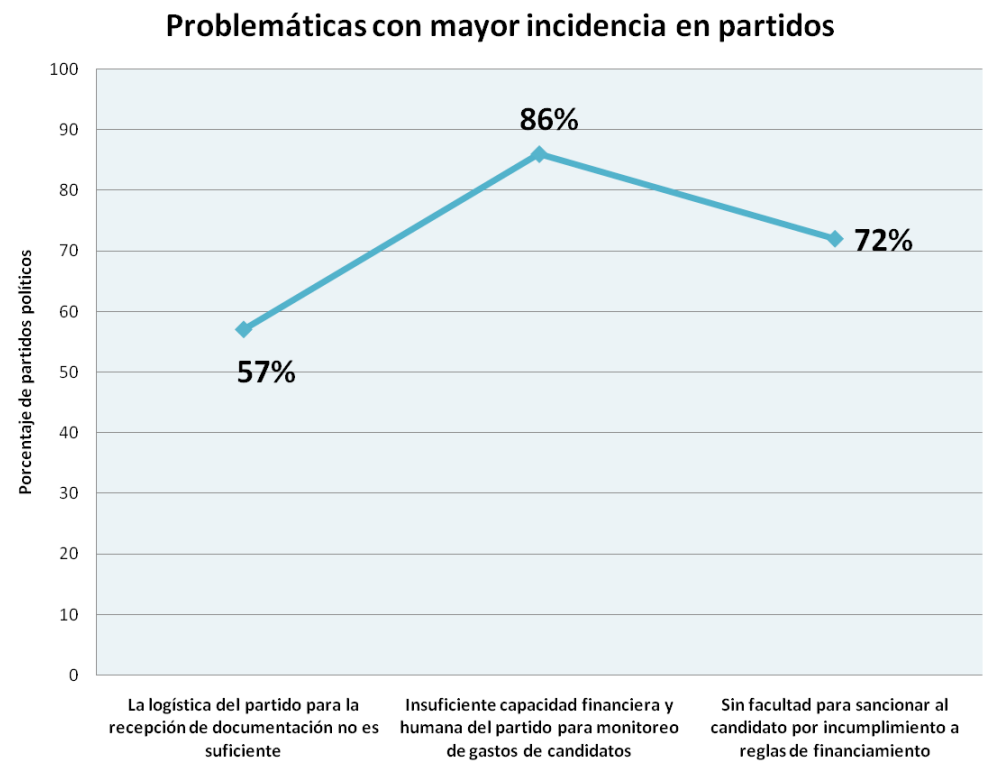

1. En las gráficas 1 y 2 se observan que son nueve los problemas indirectos más frecuentes que los partidos describen del proceso de la integración de los informes. Hay tres aspectos en los principales problemas de integración en que los partidos coinciden al 100\%. El primero de ellos es la falta de responsabilidad del candidato en la comprobación de sus gastos (el resto se verá infra, puntos 2 y 3). Todos los partidos políticos reportan este problema ya que los candidatos y su equipo de campaña tienden a desestimar el cumplimiento de la rendición de cuentas de los ingresos y egresos realizados. El 86\% de los partidos políticos reconoció que uno de los grandes desafíos encontrados es que los candidatos reciben y manejan recursos privados en forma directa, y no a través del partido como lo establece el reglamento correspondiente, lo que se traduce en un control imposible del financiamiento privado. Además, debido a que la comprobación del financiamiento privado es demasiado específica, laboriosa y minuciosa y el tope es limitado, los candidatos tienden a no registrarlo y buscar otras formas indirectas de obtenerlo. 
Esta revista forma parte del acervo de la Biblioteca Jurídica Virtual del Instituto de Investigaciones Jurídicas de la UNAM

2. La integración incorrecta de los comprobantes, es un problema en todos los partidos políticos. Lo anterior obedece a que los candidatos no cumplen con la comprobación de ingresos y egresos de acuerdo a los requerimientos de la UFRPP y el reglamento. Ello los ha obligado a establecer un proceso de seguimiento personalizado a los candidatos durante las campañas electorales para solicitar la información de comprobación en forma permanente, ofrecer asesoría y detectar anomalías en el uso de financiamiento privado. Otra de las estrategias que algunos partidos políticos han realizado es que entregan de forma parcial el financiamiento a cada candidato, de tal forma que las siguientes ministraciones se dan cuando el candidato ha entregado la comprobación de gastos correspondiente al monto entregado anteriormente. Algunos de ellos han tomado las medidas de establecer un compromiso de obligatoriedad a través de cartas compromisos o de sanciones internas para asegurar la correcta comprobación de los gastos.

3. La totalidad de los partidos reconoció que los coordinadores financieros que los candidatos nombran, y que tienen la responsabilidad del manejo mancomunado de las cuentas de los candidatos, no cuentan con el perfil contable o financiero adecuado o en su defecto con experiencia en el campo. Este problema se traduce en una mayor necesidad de capacitación y asesoría requerida aun en conceptos básicos del control de gastos.

4. El 57\% de los partidos políticos sostienen que los candidatos tienen dificultades para comprobar gastos, debido a que las campañas son realizadas en zonas rurales que no cuentan con los recursos fiscales o la infraestructura requerida para obtener la comprobación de los gastos, como gasolina, alimentos, propaganda, etcétera.

5. De los problemas con mayor incidencia que los partidos refieren respecto a su propio ejercicio, sobresale que el $86 \%$ de estos reconoce que cuentan con capacidad financiera y humana insuficiente para monitorear y compulsar los gastos de cada una de las campañas a su cargo, por lo que el control se realiza por muestreo reducido y se ven obligados a confiar en la veracidad de los datos.

6. Además, el $72 \%$ de los partidos coinciden en que no tienen la facultad de obligar a los candidatos a cumplir con el compromiso de realizar en forma expedita y eficiente la comprobación de los egresos y sujetarse a los topes de financiamiento privado establecidos. Generalmente los candidatos utilizan financiamiento privado sin límite y 
Esta revista forma parte del acervo de la Biblioteca Jurídica Virtual del Instituto de Investigaciones Jurídicas de la UNAM www.juridicas.unam.mx

no lo reportan al partido, pero debido a que la UFRPP actualmente cuenta con un programa de monitoreo de gran eficiencia, en las revisiones realizadas surge una gran cantidad de publicidad que no ha sido reportada por el partido debido a que los candidatos no han dado a conocer estos gastos de campaña. Esta falta resulta en sanciones administrativas y monetarias significativas para los partidos políticos.

\section{Gráfica 3. Número de versiones realizadas del informe de campaña por parte de los partidos}

\section{Cantidad Versiones}

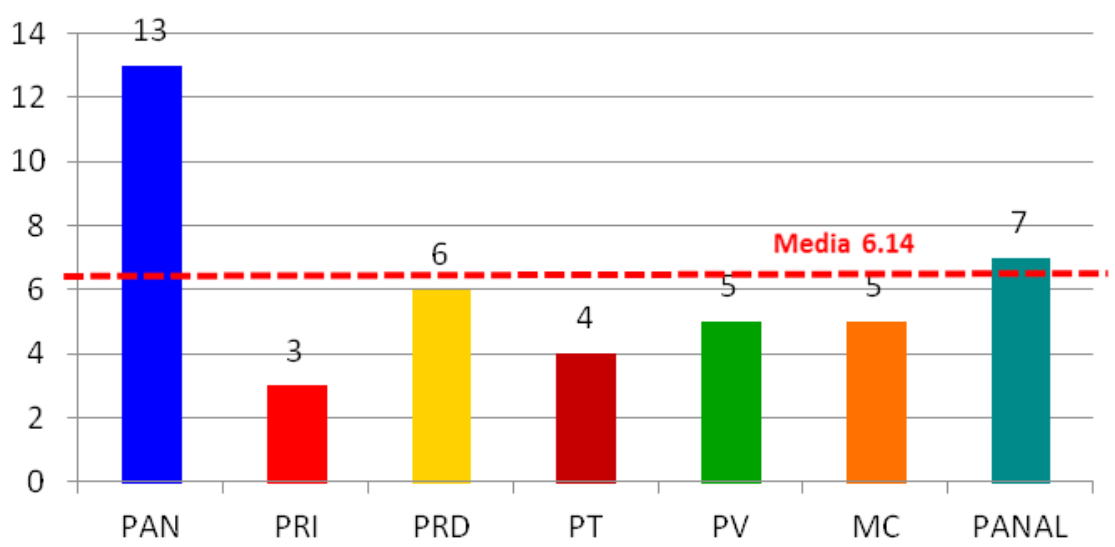

Gráfica 4. Variaciones de los ingresos y egresos reportados por partidos

\section{Variaciones de Ingresos y Egresos}

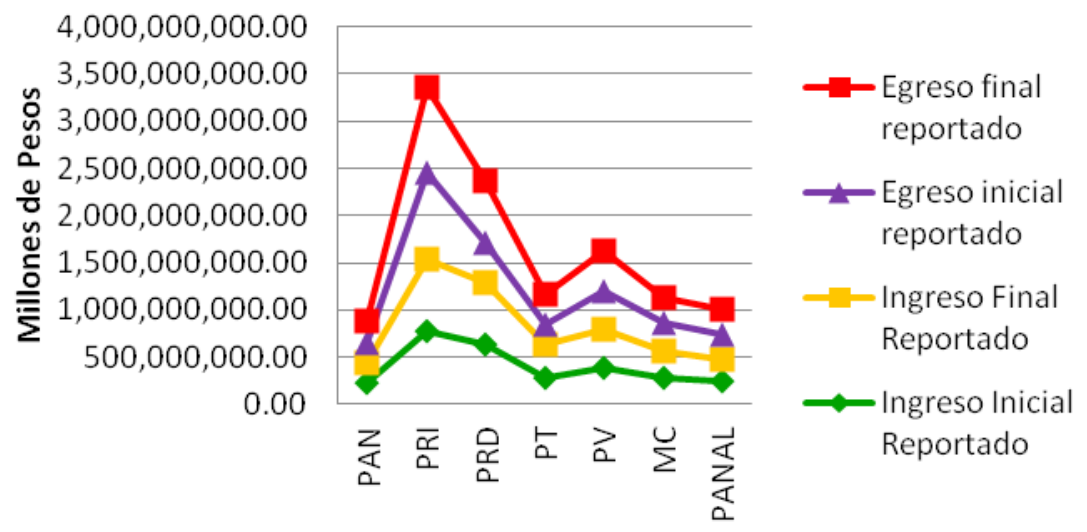


7. El nivel de especificidad en la información y el detalle exigido en los formatos de informes no ha logrado incidir en la calidad de la información que los partidos deben presentar, ya que es entregada generalmente con faltas a los lineamientos y reglas establecidas (gráfica 3)

8. El alto número de versiones de los informes que los partidos políticos entregan, producto de las observaciones efectuadas por la UFRPP, con un promedio de 6.1428 versiones; determina que de inicio la información presentada no es confiable y esto coloca en un punto crítico la calidad de los informes (gráfica 4).

9. La variación de las cifras reportadas por los partidos políticos en sus ingresos es considerable, pero en los egresos se observa una variación mayor a tal magnitud, que se considera crítica.

10. Los egresos sin reportar se van acreditando conforme aumenta el número de versiones de informes, lo que demuestra que los partidos políticos únicamente reportan gastos en función de lo que la UFRPP les acredita, por lo que se puede presumir que la información que presentan los partidos no es confiable, útil y objetiva.

11. Las omisiones de los partidos políticos o faltas de no hacer, incrementan considerablemente la actividad fiscalizadora de la UFRPP y suponen nuevas acciones y diligencias para conseguir la verificación de lo expresado u omitido en los informes. 
Esta revista forma parte del acervo de la Biblioteca Jurídica Virtual del Instituto de Investigaciones Jurídicas de la UNAM www.juridicas.unam.mx

DOl: http://dx.doi.org/10.22201/iij.24487910e.2013.4.10040

http://biblio.juridicas.unam.mx

Tabla 1. Plazos de entrega de informes de campaña en el mundo

\begin{tabular}{|c|c|c|c|c|}
\hline \multicolumn{2}{|c|}{ Tipo de informe } & $\begin{array}{l}\text { Cantidad } \\
\text { de países }\end{array}$ & Países & Plazos \\
\hline \multirow{7}{*}{\multicolumn{2}{|c|}{ Ordinarios }} & 1 & Costa Rica & $\begin{array}{c}\text { Cada mes } \\
\text { y cada tres } \\
\text { meses }\end{array}$ \\
\hline & & 1 & EEUU & 31 de enero \\
\hline & & 2 & Guatemala, Israel & Marzo \\
\hline & & 1 & República Checa & 1 de abril \\
\hline & & 1 & Perú & $\begin{array}{l}\text { Seis meses } \\
\text { después }\end{array}$ \\
\hline & & 3 & $\begin{array}{l}\text { Alemania, Austria, } \\
\text { Dinamarca }\end{array}$ & $\begin{array}{l}\text { Dentro } \\
\text { del año } \\
\text { siguiente }\end{array}$ \\
\hline & & 7 & $\begin{array}{c}\text { Australia, Francia, Japón, } \\
\text { Honduras, Nicaragua, } \\
\text { Noruega, Turquía }\end{array}$ & $\begin{array}{c}\text { No hay } \\
\text { datos sobre } \\
\text { fecha }\end{array}$ \\
\hline \multirow{2}{*}{$\begin{array}{c}\text { De } \\
\text { campaña }\end{array}$} & $\begin{array}{l}\text { Preliminar } \\
\text { y final }\end{array}$ & 4 & \multicolumn{2}{|c|}{$\begin{array}{c}\text { Bielorrusia, Croacia, República } \\
\text { Dominicana, Armenia }\end{array}$} \\
\hline & Final & 2 & Andorra, Venezuela. & $\begin{array}{l}\text { De } 45 \text { en } \\
\text { adelante }\end{array}$ \\
\hline \multirow{3}{*}{\multicolumn{2}{|c|}{ Ambos }} & 10 & $\begin{array}{l}\text { Azerbaiyán, Eslovaquia, } \\
\text { Italia, Ucrania, Bosnia y } \\
\text { Herzegovina, Chile, Estonia, } \\
\text { Georgia, Rusia, Serbia }\end{array}$ & 1 a 30 \\
\hline & & 13 & $\begin{array}{l}\text { Albania, Bélgica, Hungría, } \\
\text { Reino Unido, Bolivia, Brasil, } \\
\text { Colombia, México, Grecia, } \\
\text { Montenegro, Nueva Zelanda, } \\
\text { Paraguay, Portugal }\end{array}$ & $31-60$ \\
\hline & & 3 & Argentina, Canadá, España & $\begin{array}{c}90 \text { en } \\
\text { adelante }\end{array}$ \\
\hline \multicolumn{2}{|c|}{ Sin datos } & 3 & Finlandia, Panamá, Suiza & \\
\hline
\end{tabular}

12. Los plazos de presentación de informes en el mundo son muy variados, por lo que no podemos evaluar el modelo mexicano a partir de este dato (tabla 1).

13. El plazo de presentación de informes financieros partidistas no es proporcional con respecto al universo fiscalizable de la UFRPP, 
Esta revista forma parte del acervo de la Biblioteca Jurídica Virtual del Instituto de Investigaciones Jurídicas de la UNAM

pues la cantidad de recursos que fiscaliza es mínima en relación con la cantidad de recursos que revisa la ASF, lo cual debería reflejarse en una variación considerable en el plazo de presentación, no obstante los partidos políticos cuentan con la mitad del tiempo de que disponen las entidades públicas.

14. De acuerdo a la opinión de los responsables de la revisión de los informes, la información contenida en el reporte es insuficiente, pero los plazos son adecuados para verificar su autenticidad, a pesar de que el plazo de presentación es extenso. Aunque cabe señalar que el hecho de que la autoridad realice actividades para recabar datos de manera concurrente al ejercicio del gasto electoral, minimiza los daños que plazos tan extensos pudieran generar en la confiabilidad de la información partidista presentada.

15. Los representantes financieros de los partidos políticos tienen la percepción que a pesar de que los plazos de entrega para los informes de campaña son extensos resultan insuficientes para integrar la información completa. Su opinión viene determinada por la existencia de una práctica generalizada de iniciar la integración de la información una vez que concluyen las campañas y no de manera concurrente al desarrollo de las mismas.

16. Del análisis de los dictámenes de validez y calificación de las elecciones presidenciales de 2006 y 2012 se concluye que el proceso de calificación de las elecciones corre en tiempos distintos al de los procesos de fiscalización de los gastos en las campañas y de los tiempos para resolver procedimientos de queja. Esto es, se confirma que la fiscalización electoral no incide en el resultado de las elecciones federales en México, por lo que bajo el actual esquema, los partidos políticos y candidatos tienen fuertes incentivos para incumplir la norma; pues generalmente cuando se llega a detectar y sancionar la conducta violatoria es muy probable que la misma haya rendido los beneficios esperados.

2. Etapa de revisión del informe y verificación documental por parte de la UFRPP, incluye la solicitud de aclaraciones y rectificaciones, y la elaboración de un dictamen y proyecto de resolución

1. La UFRPP realiza una revisión exhaustiva y rigurosa de los informes financieros partidistas, utilizando variados y completos instru- 
Esta revista forma parte del acervo de la Biblioteca Jurídica Virtual del Instituto de Investigaciones Jurídicas de la UNAM

mentos de control: desarrolla revisión documental para verificar el cumplimiento de las reglas de ingreso y egreso, verifica la información de manera muestral utilizando procedimientos de auditoría como la observación, inspección, o fiscalización en terreno, visitas, verificaciones in locuo o monitoreo de propaganda callejera; realiza cotejos y confirmaciones de operaciones con terceros y, finalmente, utiliza instrumentos de investigación para validar y ampliar los hallazgos como acceder a información bancaria y fiscal, requerir información a personas físicas y morales, o intercambiar información con otras autoridades. Pero a pesar de ello se advierten dificultades para enfrentar el problema de las malas prácticas de los sujetos obligados como son: los registros ocultos, las subdeclaraciones y los actos de simulación.

2. Durante la etapa de revisión, se dedica demasiado tiempo a la verificación de aspectos de forma de los informes partidistas.

3. Los hallazgos importantes de la UFRPP se generan a partir de la verificación de la información de los informes presentados por los partidos políticos contra la información generada previamente a través del monitoreo.

4. Las faltas sustantivas no substanciadas en los procedimientos de "notificación de oficios de errores y omisiones", logran acreditar el 4.37\% más de los ingresos reportados por los partidos políticos.

5. Las faltas sustantivas que vulneran los principios rectores son apenas el 6\% del total de irregularidades determinadas; sin embargo corresponde al $85 \%$ del total del importe de sanciones determinado por la UFRPP. 
Esta revista forma parte del acervo de la Biblioteca Jurídica Virtual del Instituto de Investigaciones Jurídicas de la UNAM

3. Etapa de sanciones del Consejo General, en su caso, y la posibilidad de impugnación ante el Tribunal Electoral del Poder Judicial de la Federación

Tabla 2. Proyectos de resolución de la UFRPP ratificados en el Consejo General del IFE

\begin{tabular}{|c|c|c|}
\hline \multicolumn{2}{|c|}{$2007-2012$} \\
\hline Procedimiento & Número & $\begin{array}{c}\text { Proyectos de resolución } \\
\text { ratificados en CG }\end{array}$ \\
\hline Quejas & 331 & 331 \\
\hline Procedimiento oficioso & 270 & 270 \\
\hline $\begin{array}{c}\text { Procedimiento } \\
\text { fiscalizador anual } \\
\text { ordinario }\end{array}$ & 38 & 38 \\
\hline Precampaña Expedito & 12 & 12 \\
\hline Precampaña Ordinario & 5 & 5 \\
\hline Precampaña Ordinario & 12 & 12 \\
\hline Campaña & 7 & 7 \\
\hline Total & 675 & 675 \\
\hline
\end{tabular}

1. La competencia del Consejo General del IFE en la resolución de los proyectos de sanción de la UFRPP relacionados a la fiscalización ordinaria, de precampañas, campañas y procedimientos oficiosos o de queja, no ha afectado las condiciones de eficacia del procedimiento sancionador, aun cuando en algunos casos la totalidad de los proyectos han sido confirmados en lo general pero no en lo particular.

2. El procedimiento de fiscalización se beneficia de que un organismo que goza de fortaleza institucional y legitimidad, como el Consejo General del IFE, tenga la competencia de aplicar las sanciones. A pesar de los cuestionamientos por su actuación en los procesos electorales de los años 2006 y 2012, aún se percibe como una de las instituciones más sólidas del país, con adecuadas garantías de autonomía, suficiencia presupuestal y procedimientos de ejecución en materia de fiscalización y sanción. ${ }^{14}$

${ }^{14}$ Sobre la percepción ciudadana en torno a la confiabilidad del IFE, $c f r$. http://www. parametria.com.mx/DetalleEstudio.php? $E=4411$, consultada el 2 de febrero de 2013. 
Esta revista forma parte del acervo de la Biblioteca Jurídica Virtual del Instituto de Investigaciones Jurídicas de la UNAM

3. La modificación del modelo puede justificarse en aras de fortalecer al IFE deslindándolo de tareas que desgastan su relación con los partidos, pero no se justifica en función de la eficacia del procedimiento de fiscalización, pues este requiere un organismo fuerte y autónomo para hacer valer las reglas, condiciones con las que cumple el IFE. La UFRPP no tiene el blindaje que por diseño tiene el IFE para protegerse de las constantes y fuertes presiones que implica la imposición de sanciones a partidos y actores políticos. Además, la UFRPP ha podido realizar su trabajo desde un espacio eminentemente técnico, que pudiera politizarse si se le confiere la competencia de aplicar sanciones.

4. Puede tener la competencia otro organismo, siempre y cuando se garantice su completa autonomía y cuente con la suficiente legitimidad para enfrentar el desgaste que implican estos procedimientos. La ASF pudiera ser una opción.

5. Más de la mitad de las resoluciones del Consejo General del IFE han sido recurridas ante el TEPJF.

6. Un tercio de las resoluciones impugnadas han sido revocadas o modificadas por el TEPJF.

7. Las principales razones por las cuales las sanciones han sido revocadas obedecen a violaciones a derechos procesales dentro del procedimiento, como emplazamientos mal realizados, omisiones, o falta de motivación y argumentación para individualizar la sanción.

8. Dentro de las principales explicaciones a las violaciones a los derechos procesales en los procedimientos se encuentran: dolo o ignorancia de los funcionarios responsables, la celeridad en el desahogo del procedimiento, dilemas conceptuales, las necesidades derivadas de la propia investigación.

\section{A modo de propuestas}

Mejorar el modelo de fiscalización en México implica que nuestros políticos modifiquen muchas de sus conductas y prácticas corruptas derivadas del principio del querer ganar la elección al costo que sea necesario. Pero sin lugar a dudas, también implica modificar el andamiaje normativo para que responda a las expectativas de una eficaz 
Esta revista forma parte del acervo de la Biblioteca Jurídica Virtual del Instituto de Investigaciones Jurídicas de la UNAM

rendicion de cuentas, capaz de garantizar la debida equidad y transparencia de nuestras elecciones.

Con el objetivo de acelerar y eficientar el proceso de integración de los informes financieros, de tal suerte que los resultados del ejercicio de fiscalización impacten en el resultado del proceso, debe incorporarse a la normatividad la realización -inmediatamente después de concluida la jornada electoral- de una fiscalización autoaplicativa destinada a verificar el cumplimiento de rubros específicos, como es el respeto a los topes generales de gasto, a partir de los propios hallazgos de la UFRPP, sin necesidad de esperar la entrega formal de informes, y con la obligación partidista de informar sobre sus prorrateos a partir de que sean requeridos.

Se propone fortalecer los monitoreos de gasto, invirtiendo mayores recursos en estos ejercicios, ampliando su alcance, e incorporando a los organismos electorales locales y organizaciones de la sociedad civil en estas tareas, toda vez que son el principal instrumento para detectar si el partido o coalición recibió recursos de fuentes prohibidas, para identificar la posibilidad de que se esté en presencia de una "doble contabilidad", de omisiones en el registro contable, o, incluso, los casos en que si se realiza el registro pero se atribuye el origen del recurso a otra fuente. En el mismo sentido, se plantea establecer un padrón obligatorio de proveedores, que incluya los prestadores de servicios de espectaculares; la investigación directa del SAT a proveedores que realicen transacciones comerciales con los partidos políticos y, finalmente, la obligación de los partidos políticos de difundir o divulgar su información financiera en su portal de Internet durante el desarrollo de las campañas.

En el ámbito de su competencia, las instancias de inteligencia, investigaciones financieras y persecutoras de delitos electorales deben fortalecer sus capacidades para presentar resultados oportunos y concluyentes, con el fin de inhibir las malas prácticas violatorias a las reglas de financiamiento y gasto electoral. No son el IFE ni la UFRPP los únicos responsables en este proceso. Pero sobre todo, más que establecer mayores regulaciones y estrategias de control, el modelo mexicano requiere generar mayores incentivos para el cumplimiento de las reglas, reconociendo la posibilidad de que los candidatos y precandidatos sean sujetos imputables o destinatarios de las sanciones. Se debe evitar la sobrerregulación, procurando más bien aplicar criterios prácticos, aligerando el nivel restrictivo de las reglas, incrementando 
Esta revista forma parte del acervo de la Biblioteca Jurídica Virtual del Instituto de Investigaciones Jurídicas de la UNAM

considerablemente los montos de los topes de gasto y permitiendo en algunas circunstancias las aportaciones de personas morales con fines mercantiles o comerciales, a efecto de motivar mayor transparencia.

La investigación nos demuestra que, si bien la combinación de campañas con controles precarios da lugar no tanto a incidentes de corrupción sino a la corrupción misma del sistema, no se puede abusar en la cantidad y magnitud de las restricciones y los controles.

Se requiere un modelo menos restrictivo, que no tenga la necesidad de sustituir los rígidos principios del derecho penal que imperan en los procedimientos sancionadores electorales, para acreditar con mayor eficacia las violaciones a las reglas de financiamiento y gasto electoral, resulta conveniente transitar a un modelo menos restrictivo, un modelo que no establezca tantas restricciones, que no genere tantos límites y prohibiciones estrictas, para no fomentar la ilegalidad, la simulación, y la pérdida de credibilidad en las instituciones y los procesos electorales. Entre más restrictivas sean las reglas de financiamiento más complicado resulta hacerlas valer. Las reglas restrictivas solamente tienen éxito en países con regímenes parlamentarios con plazos muy cortos de campaña, pues en consecuencia resultan muy poco exigidas, pero éste no es el caso.

Finalmente, se debe reconocer que hay poco por hacer para fiscalizar los gastos destinados a actividades como la compra de votos. Detrás de la compra-venta del voto se encuentra la regla de la oferta y la demanda, de ahí que la solución a este problema pasa por mejorar las condiciones socioeconómicas del país. Requiere del ataque frontal a las enormes desigualdades socioeconómicas que generan condiciones propicias para la práctica de esta conducta. Requiere generar condiciones para que, como en la idea de Rousseau, no haya nadie tan pobre que tenga necesidad de venderse y nadie tan rico que pueda comprar a alguien.

\section{Fuentes consultadas}

Castillo, Pilar del y Zovatto, Daniel (eds.), La financiación de la política en Iberoamérica, San José, Costa Rica, Instituto Interamericano de Derechos Humanos, 1998.

Chacón Rojas, Oswaldo, Dinero del crimen organizado y fiscalización electoral, México, Fontamara, 2011. 
Esta revista forma parte del acervo de la Biblioteca Jurídica Virtual del Instituto de Investigaciones Jurídicas de la UNAM

Córdova, Lorenzo y Murayama, Ciro, Elecciones, dinero y corrupción. Pemexgate y Amigos de Fox, México, Cal y Arena, 2006.

Ferreira Rubio, Delia (ed.), Financiamiento de partidos políticos, Buenos Aires, Centro Interdisciplinario de Estudios sobre el Desarrollo Latinoamericano-Konrad Adenauer Stiftung, 1997.

SUP-RAP-017/97, 26 de junio de 1997.

Zovatto, Daniel, "América Latina", en CArrillo, Manuel et al. (coords.), Dinero y contienda político-electoral. Reto de la democracia, México, Fondo de Cultura Económica, 2003.

\section{Internet}

Acuerdo General del IFE, sesión extraordinaria del Consejo General celebrada el 16 de diciembre de 2011 CG434/2011 (presidente), CG435/2011 (senador), CG436/2011(diputados), http://www.ife. org.mx/documentos/proceso_2011-2012/preparacion.html.

Global Commision on Elections, Democracy and Security, Deepening Democracy: A strategy for improving the integrity of elections worldwide, septiembre de 2012, http://www.global-commission.org/sites/ global-commission.org/files/DeepeningDemocracyFinalReport.pdf.

http://www.global-commission.org/sites/global-commission.org/files/ DeepeningDemocracyFinalReport.pdf.

IFE, Comunicado de prensa de 23 de noviembre de 2011, http://www. ife.org.mx/documentos/proceso_2011-2012/preparacion.html.

Murayama, Ciro, "Consecuencias económicas de la reforma electoral”, Nexos, México, octubre de 2007, http://www.nexos.com.mx/?P $=$ leerarticulo\&Article $=660960$.

Political Finance Regulations around the World. An Overview of the International IDEA Database, http://www.idea.int/publications/political-finance-regulations/loader.cfm?csModule=security/ getfilespageid $=52121$.

Political finance regulation: The Global Experiencie, http://www. ifes.org/ /media/Files/Publications/Books/2009/Political\%20 Finance\%20Regulation\%20The\%20Global\%20Experiencel Political_Finance_Regulation_The_Global_Experience.pdf.

Sobre la percepción ciudadana en torno a la confiabilidad del IFE, $c f r$. http://www.parametria.com.mx/DetalleEstudio.php?E=4411. 